\title{
The Determinants of the Efficiency of Commercial Banks
}

\author{
Xian Zhou, Zhiyu An * \\ ${ }^{a}$ School of Economics and Management,Nanjing University of Science and Technology,China \\ *Corresponding author:Zhiyu An,Associate Professor,zhiyu_ann@163.com
}

\begin{abstract}
With the development of social economy, commercial banks are the lifeblood of our national economy, which play an absolutely fundamental role in the modern financial markets. This paper uses the DEA method to measure the efficiency of 16 listed commercial banks from 2010 to 2015.To investigate the determinants of efficiency, we use the Tobit model. We find the efficiency of the state-owned commercial banks is lower than the efficiency of other banks. Asset scale, capital adequacy ratio, non-performing loan ratio,cost-to-income ratio are negatively associated with bank efficiency.
\end{abstract}

Keywords: bank efficiency; DEA; Tobit model; influence factors

\section{Introduction}

\subsection{Research background}

With the development of social economy, commercial banks account for a very large proportion in the modern financial market, and play an obvious role in the development in our country. In recent years, the international financial environment is changing constantly and unpredictably. Commercial banks face the straight challenge of foreign bank under open economy. If commercial banks want to continue to develop, they have to make up for their own lack of innovation, develop new services and products, closely follow the trend of the times and meet customer demand. the overall situation is not optimistic.

So we must pay attention to the efficiency of commercial banks and its influence factors. Take actions to improve the efficiency of commercial banks in our country.

\subsection{Literature review}

DEA is a non-parametric technique which can be used with multiple input and multiple output. The model of DEA was proposed by Charnes, Cooper and Rhodes (1978). DEA is considered to be the most effective way for performance evaluation.

Foreign scholars study the commercial bank with DEA method as early as 1950s. Alhadeff $^{1}$ analysis the business data of over 200 banks in California between 1938 and 1950 . Jackson et al. ${ }^{2}$ study the Turkish bank efficiency and find bank size and profitability are positively associated with bank efficiency. However, Altunbas et al. ${ }^{3}$ find bank size are negatively associated with bank efficiency according to the European bank. Our country study in this respect quite late. Zhu et al. ${ }^{4}$ find that the overall efficiency of joint-stock commercial 
banks is much higher than that of state-owned commercial banks. Zhao et al. ${ }^{5}$ study the big four banks and find that market concentration, market share and profitability are negatively associated with bank efficiency.Yao et al. ${ }^{6}$ find profitability has positive impact on bank efficiency and the effect of LDR is negative.

\section{Experimental}

\subsection{Bank efficiency}

The measures of bank efficiency are obtained using DEA method. We specify our model based upon the standard financial intermediation approach to evaluate the relative efficiency of banks. On the basis of a large number of literature, the paper choose bank staff, operating expenses and shareholders' equity as inputs, and interest income and non-interest income as outputs.

The paper selects 16 listed commercial banks, including five state-owned banks (ICBC, ABC, BOC, CCB and BCM), eight joint-stock commercial banks (CEB, HXB, CMBC, PAB, SPDB, CIB, CMB and CNCB) and three city commercial banks (BOB, NJCB and NBCB). The paper selects data from 2010 to 2015. The dataset is compiled from two main sources: (1)the CSMAR database, and (2)the annual reports of banks .

\subsubsection{Main results}

Table 1 presents the efficiency scores. The average technical efficiency is 0.9543 , the average pure technical efficiency is 0.9883 and average scale efficiency is 0.9657 . The inefficiency of commercial banks is partly caused by poor bank management, mainly caused by the inefficiency of scale efficiency.

Technical efficiency and pure technical efficiency of commercial bank falls into decline in 2010, stable in the next two years, and rise significantly after 2013. Scale efficiency is stable in the six years. It shows that the change of pure technical efficiency is a major cause of the changes of technical efficiency.

\subsection{Banking ownership structure}

Due to the uncomplete shareholding reform of state-owned banks, state property have not changed, finance resource is distributed unevenly. So although the efficiency of state-owned banks is improved, but still far lower than other commercial banks. So the paper makes a distinction between state-owned banks and other banks next.

Table 2 shows efficiency of stated-owned banks and other banks. The technical efficiency of state-owned banks is lower than others between 2010 and 2015, which verifies the comments above. The scale efficiency of the state-owned banks is usually much lower than other banks (especially joint-stock commercial banks). The pure technical efficiency of state-owned banks is higher than joint-stock commercial banks, while the pure technical efficiency score of city 
Table 1. Bank efficiency from 2010 to 2015

\begin{tabular}{|c|c|c|c|c|c|c|c|c|c|c|c|c|c|c|c|c|c|c|}
\hline & & $\mathrm{BOC}$ & $\mathrm{CCB}$ & ICBC & $\mathrm{ABC}$ & $\mathrm{CIB}$ & $\mathrm{BCM}$ & SPDB & PAB & CMBC & $\mathrm{CMB}$ & CNCB & CEB & HXB & BOB & NJCB & NBCB & avg \\
\hline \multirow{7}{*}{ TE } & 2010 & 1.000 & 0.964 & 0.972 & 0.914 & 1.000 & 0.927 & 0.892 & 0.916 & 0.997 & 1.000 & 0.91 & 0.984 & 1.000 & 1.000 & 1.000 & 0.903 & 0.961 \\
\hline & 2011 & 1.000 & 0.929 & 0.98 & 0.832 & 1.000 & 0.881 & 0.982 & 0.926 & 1.000 & 1.000 & 0.922 & 0.875 & 1.000 & 1.000 & 0.95 & 0.883 & 0.947 \\
\hline & 2012 & 1.000 & 0.939 & 0.987 & 0.818 & 1.000 & 0.899 & 0.999 & 0.944 & 1.000 & 0.913 & 0.809 & 0.99 & 1.000 & 1.000 & 1.000 & 0.894 & 0.949 \\
\hline & 2013 & 1.000 & 0.905 & 0.998 & 0.784 & 1.000 & 0.814 & 1.000 & 0.881 & 1.000 & 0.912 & 0.848 & 1.000 & 0.941 & 1.000 & 1.000 & 0.998 & 0.943 \\
\hline & 2014 & 1.000 & 0.894 & 0.976 & 0.776 & 1.000 & 0.914 & 0.982 & 1.000 & 1.000 & 1.000 & 0.93 & 1.000 & 1.000 & 1.000 & 1.000 & 0.961 & 0.965 \\
\hline & 2015 & 1.000 & 0.91 & 0.986 & 0.815 & 1.000 & 0.964 & 0.985 & 1.000 & 1.000 & 0.931 & 0.923 & 0.963 & 0.969 & 1.000 & 1.000 & 0.93 & 0.961 \\
\hline & avg & 1.000 & 0.9235 & 0.9832 & 0.8232 & 1.000 & 0.8998 & 0.9733 & 0.9445 & 0.9995 & 0.9593 & 0.8903 & 0.9687 & 0.985 & 1.000 & 0.9917 & 0.9282 & 0.9543 \\
\hline \multirow{7}{*}{ PTE } & 2010 & 1.000 & 1.000 & 1.000 & 1.000 & 1.000 & 1.000 & 1.000 & 0.96 & 1.000 & 1.000 & 0.949 & 0.995 & 1.000 & 1.000 & 1.000 & 1.000 & 0.994 \\
\hline & 2011 & 1.000 & 0.991 & 1.000 & 1.000 & 1.000 & 1.000 & 1.000 & 0.957 & 1.000 & 1.000 & 0.934 & 0.878 & 1.000 & 1.000 & 1.000 & 1.000 & 0.985 \\
\hline & 2012 & 1.000 & 1.000 & 1.000 & 1.000 & 1.000 & 1.000 & 1.000 & 0.958 & 1.000 & 0.913 & 0.908 & 0.996 & 1.000 & 1.000 & 1.000 & 1.000 & 0.986 \\
\hline & 2013 & 1.000 & 0.982 & 1.000 & 1.000 & 1.000 & 0.971 & 1.000 & 0.89 & 1.000 & 0.914 & 0.88 & 1.000 & 0.945 & 1.000 & 1.000 & 1.000 & 0.974 \\
\hline & 2014 & 1.000 & 1.000 & 1.000 & 1.000 & 1.000 & 0.997 & 1.000 & 1.000 & 1.000 & 1.000 & 0.959 & 1.000 & 1.000 & 1.000 & 1.000 & 1.000 & 0.997 \\
\hline & 2015 & 1.000 & 1.000 & 1.000 & 1.000 & 1.000 & 1.000 & 1.000 & 1.000 & 1.000 & 1.000 & 0.928 & 0.976 & 0.993 & 1.000 & 1.000 & 1.000 & 0.994 \\
\hline & avg & 1.000 & 0.9955 & 1.000 & 1.000 & 1.000 & 0.9947 & 1.000 & 0.9608 & 1.000 & 0.9712 & 0.9263 & 0.9742 & 0.9897 & 1.000 & 1.000 & 1.000 & 0.9883 \\
\hline \multirow{7}{*}{$\mathrm{SE}$} & 2010 & 1.000 & 0.964 & 0.972 & 0.914 & 1.000 & 0.927 & 0.892 & 0.954 & 0.997 & 1.000 & 0.959 & 0.989 & 1.000 & 1.000 & 1.000 & 0.903 & 0.967 \\
\hline & 2011 & 1.000 & 0.937 & 0.98 & 0.832 & 1.000 & 0.881 & 0.982 & 0.967 & 1.000 & 1.000 & 0.987 & 0.996 & 1.000 & 1.000 & 0.95 & 0.883 & 0.962 \\
\hline & 2012 & 1.000 & 0.939 & 0.987 & 0.818 & 1.000 & 0.899 & 0.999 & 0.986 & 1.000 & 1.000 & 0.891 & 0.994 & 1.000 & 1.000 & 1.000 & 0.894 & 0.963 \\
\hline & 2013 & 1.000 & 0.922 & 0.998 & 0.784 & 1.000 & 0.838 & 1.000 & 0.991 & 1.000 & 0.998 & 0.963 & 1.000 & 0.995 & 1.000 & 1.000 & 0.998 & 0.968 \\
\hline & 2014 & 1.000 & 0.894 & 0.976 & 0.776 & 1.000 & 0.917 & 0.982 & 1.000 & 1.000 & 1.000 & 0.97 & 1.000 & 1.000 & 1.000 & 1.000 & 0.961 & 0.967 \\
\hline & 2015 & 1.000 & 0.91 & 0.986 & 0.915 & 1.000 & 0.964 & 0.985 & 1.000 & 1.000 & 0.931 & 0.995 & 0.986 & 0.975 & 1.000 & 1.000 & 0.93 & 0.967 \\
\hline & avg & 1.000 & 0.9277 & 0.9832 & 0.8398 & 1.000 & 0.9043 & 0.9733 & 0.9796 & 0.997 & 0.9763 & 0.9608 & 0.993 & 0.985 & 1.000 & 0.95 & 0.9282 & 0.9657 \\
\hline
\end{tabular}

Table 2. Efficiency of state-owned banks and other banks

\begin{tabular}{|c|c|c|c|c|c|c|c|}
\hline & & 2010 & 2011 & 2012 & 2013 & 2014 & 2015 \\
\hline \multirow{3}{*}{ TE } & State-owned banks & 0.9554 & 0.9244 & 0.9286 & 0.9002 & 0.912 & 0.935 \\
\hline & & & & & & & \\
\hline & Other banks & 0.9638 & 0.958 & 0.959 & 0.9618 & 0.9885 & 0.9728 \\
\hline \multirow{3}{*}{ PTE } & State-owned banks & 1.000 & 0.9982 & 1.000 & 0.9906 & 0.9994 & 1.000 \\
\hline & & & & & & & \\
\hline & Other banks & 0.9913 & 0.979 & 0.9795 & 0.9663 & 0.9963 & 0.9906 \\
\hline \multirow{3}{*}{ SE } & State-owned banks & 0.9443 & 0.9075 & 0.9286 & 0.8855 & 0.8908 & 0.9438 \\
\hline & & & & & & & \\
\hline & Other banks & 0.9563 & 0.9706 & 0.9663 & 0.99315 & 0.9826 & 0.9753 \\
\hline
\end{tabular}


commercial banks is 1 , which shows the operation and management state is the best. In state-owned banks, the technology and pure technical efficiency of BCM and ABC is lower. Though the technical efficiency of state-owned banks is low, due to their large size and nature of property right, they have more resources and attract more talents. So their management is better. Compared to other commercial banks, the inefficiency of state-owned banks is most caused by the inefficiency of scale efficiency. The state-owned banks are at the decreasing stage of the scale return, while the city commercial banks are at the increasing stage.

Due to the large scale of state-owned banks and most joint-stock commercial banks, blind expansion of assets is not only unable to improve the efficiency, but also reduces the efficiency because of management problems. The asset size of city commercial banks and a part of joint-stock commercial bank is not large due to develop late. They are still on the stage of scale increasing returns, so the enlargement of the scale is useful to improve the efficiency.

\subsection{Influence factor of the efficiency}

Bank efficiency scores range between 0 and 1 by DEA method. The data are censored, so we uses Tobit model next. There are many factors that can influence bank efficiency, according to much literature, this paper studies the effect of the nature of property right, asset scale, non-performing loan ratio, loan-to-deposit ratio, capital adequacy ratio, return on assets, cost-to-income ratio and the proportion of fees and commissions on bank efficiency. We estimate the following model:

$Y_{i}=\alpha_{0}+\alpha_{1}$ dummy $_{\mathrm{SOB}_{\mathrm{it}}}+\alpha_{2} A S_{i t}+\alpha_{3} L D R_{i t}+\alpha_{4} R O A_{i t}+\alpha_{5} C A R_{i t}+\alpha_{6} N P L_{i t}+\alpha_{7} C I R+\alpha_{8} F C I+\varepsilon_{i t}$ where dummysoBit is a dummy variable, which takes the value 1 if it is state-owned commercial bank. $\mathrm{AS}_{\text {it }}$ is asset scale of banks. (The paper takes logarithm of total assets.) LDR is loan-to-deposit ratio, which reflects the asset allocation. ROA is return on assets which is a index of profitability. CAR is capital adequacy ratio, measuring a bank's risk of insolvency from excessive losses. NPL is non-performing loan ratio, the important indicators of credit assets security. CIR is cost-to-income ratio. CIR is also an index of bank profitability. FCI is the proportion of fees and commissions, Fees and commissions is an important part of the intermediate business income.

Table 3 shows the empirical results. LDR, ROA and FCI are not significant, so we eliminate the three factors in the multivariate analysis next. In order to avoid the multicollinearity problem between the explanatory variables(the correlation coefficient between dummysoBit and $\mathrm{AS}_{\text {it }}$ is 0.772 ), model 9 considers dummysoBit while model 10 consideres $\mathrm{AS}_{\text {it. }}$

Model 1 shows the efficiency of state-owned banks is higher, however, it does not match the reality clearly. So after controlling for other factors in model 9, it shows that the efficiency of the state-owned commercial banks is lower than the efficiency of other banks, consistent with the DEA score calculated in the third part. 
Table 3. Empirical results

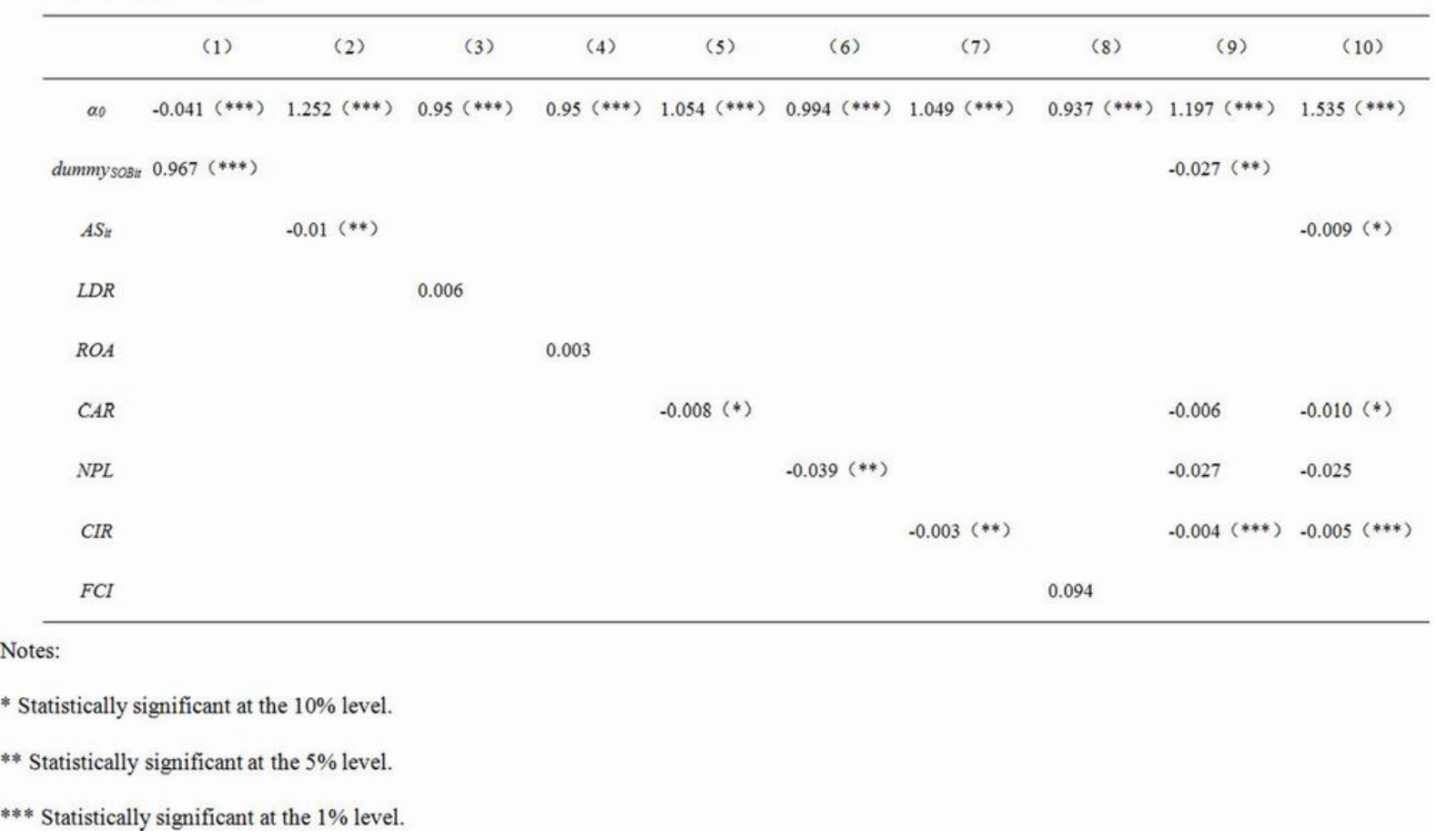

Model 2 shows that the asset scale is negatively associated with bank efficiency, meaning that the blind expansion of assets do not always improve bank efficiency. Instead, most of the commercial banks in China have been at the decreasing stage of the scale return. The enlargement of scale will reduce the efficiency, consistent with the analysis results in the third part. After controlling for other variables in model 10, the result remains the same.

Model 5 shows the negative influence of CAR on bank efficiency. It is opposite to other papers where CAR has a negative correlation with bank efficiency. CAR is an index to measure bank stability. Generally speaking, the higher the CAR is, the greater the ability to take default risk is. But Blum think if the cost of raising capital is too high, banks may engage in risky business to increase current earnings, and thus improve the capital adequacy ratio, which will ultimately increase the risk of bank. Furlong and Keeley think strict capital regulation will increase risk and probability of bankruptcy. Yang et al. think when interest rates rise, although it can increase the bank returns, improving CAR will increase interest rate risk. ${ }^{7}$ Unlike other countries, commercial banks in our country generally have the recessive guarantee of government, especially the state-owned banks. So CAR plays an important role in supervision, rather than withstanding risk to improve bank efficiency. ${ }^{8}$

Model 6 shows that non-performing loan ratio has a negative impact on bank efficiency. Non-performing loan ratio is an important index to measure the safety of the loans. The lower the ratio is, the safer the loans are. Banks can improve the efficiency by lowering the rate of non-performing loans. After controlling for other variables, the coefficient is still significantly negative in model 10 , but not significant in model 9 . It may be caused by the correlation between NPL and dummysoBit, so the explanation of NPL is absorbed by dummysoBit. 
In model 7, 9 and 10, the coefficient of cost-to-income ratio is significantly negative, which is consistent with previous studies. CIR is also an index to measure bank profitability as same as ROA. ROA is calculated by dividing annual earnings by its total assets, CIR equals a company's operating costs divided by its operating income. The limitation of ROA is that it can not reflect the cost of capital. The result which shows that the coefficient of CIR is significant but ROA is not tells that bank efficiency can be improved by reducing the cost, such as operational expenses and management expenses.

\section{Conclusion}

This paper uses the DEA method to measure the efficiency of 16 commercial banks from 2010 to 2015. And then to investigate the determinants of efficiency, we use the Tobit model. We find the efficiency of the state-owned commercial banks is lower than the efficiency of other banks. Asset scale, capital adequacy ratio, non-performing loan ratio, cost-to-income ratio are negatively associated with bank efficiency. However, loan-to-deposit ratio, capital adequacy ratio and the proportion of intermediary business are not significantly related to bank efficiency. Research shows that expanding the scale of assets blindly cannot improve the efficiency of commercial bank, we can improve the bank efficiency by reducing asset scale, controling capital adequacy ratio effectively, reducing non-performing assets and bank cost, such as banking business and management fees.

\section{References}

1. D. A.Alhadeff, Monopoly and Competition in Commercial Banking, University of California Press. 06(1954)24-46

2. P. M. Jackson, IMD.Feth, Evaluating the Technical Efficiency of Turkish Commercial Banks: An Application of DEA and Tobit Analysis. International DEA Symposium in University of Queensland,Working Paper, 2000.

3. Y. Altunbas, E.P.M. Gradener, P. Molyneux, B. Moore, Efficiency in European Banking, European Economic Review, 45(2001)1931-1955

4. N. Zhu, X. Zhuo, Y. Dong, The empirical analyses on the efficiency of state-owned commercial banks in China, Management World. 02(2004)18-26

5. X. Zhao,K. Ling, The empirical study of influencing the efficiency of banking industry in our country, Decision-making reference. 14(2001)24-29

6. J.L. Yao, D.X. Mao, The evaluation and analysis of joint-stock commercial bank efficiency based on DEA -Tobit method, Journal of Shanghai University. 15(2009)436-440

7. Y. Yang, R.W. Lin, Does the lower risk bank have,the higher the capital adequacy ratio is?-Based on the investigation of the interest rate risk, Finance and Economics. 05(2013)10-17

8. Q. Tian, F.Y. Li, The emporocal analysis of the correlation of commercial bank 
efficiency and capital adequacy ratio, Journal of Hunan University. 01(2012)92-96 